\title{
Investigation of hot-water flooding after steam injection to improve oil recovery in thin heavy-oil reservoir
}

\author{
Zhengbin $\mathrm{Wu}^{1,2} \cdot$ Huiqing Liu ${ }^{2}$
}

Received: 15 November 2017 / Accepted: 5 October 2018 / Published online: 22 October 2018

(c) The Author(s) 2018

\begin{abstract}
Cyclic steam stimulation (CSS) is one of the popular methods to recovery heavy oil reserves that play an important role in supplying the energy consumption over the world. To solve the problems during the late CSS, we perform the feasibility study of hot-water flooding (HWF) after CSS with laboratory experiments and numerical simulation. The experimental results revealed the optimized water temperature to conduct HWF is $120^{\circ} \mathrm{C}$ and the correct moment to convert is when the oil recovery of steam injection reaches $20 \%$. Based on the geological properties of Jinlou oilfield in China, a series of numerical simulations were run to analyze the influence of several sensitive factors. It is necessary to transform development method because there are large quantities of remaining oil assembling at the inter-well region during the late stage of CSS and this after analyzing the oil saturation, reservoir temperature and oil viscosity distribution. The effect of HWF in reverse-rhythm and compound-rhythm reservoir is satisfactory, but is poor in positive-rhythm reservoir. It is suitable to reservoirs with thickness lower than $5 \mathrm{~m}$ and permeability variation coefficient less than 0.3 . This study can provide a reference for enhanced oil recovery for thin heavy oil reservoirs after steam injection.
\end{abstract}

Keywords Heavy oil $\cdot$ Steam injection $\cdot$ Hot-water flooding $\cdot$ Enhanced oil recovery $\cdot$ Physical experiment $\cdot$ Numerical simulation

\section{Introduction}

With the development of global economy, oil demand increases rapidly. As conventional oils have been developed in the past several decades, the heavy oil has attracted worldwide attention due to its abundant reserves. The techniques that are applied for enhanced heavy oil recovery also attract extensive attention. Generally, there are two main development patterns for heavy oil reservoirs, cold production and thermal production. The cold production methods include natural depletion, water flooding and chemical flooding (e.g., gas flooding, surfactant flooding, polymer flooding, alkali flooding, ASP compound flooding and foam flooding) which is applied to heavy oil reservoirs with relatively low

Zhengbin $\mathrm{Wu}$

wuzb1100@126.com

$1 \quad$ MOE Key Laboratory of Tectonics and Petroleum Resources, China University of Geosciences, Wuhan 430074, Hubei, People's Republic of China

2 China University of Petroleum, Beijing 102249, Beijing, People's Republic of China viscosity. While the thermal recovery is the fundamental method used for heavy oil reservoirs with high viscosity and it mainly includes two kinds of reservoir heating types. One is injecting thermal fluid into reservoir, such as cyclic steam stimulation (CSS), steam flooding (SF), steam-assisted gravity drainage (SAGD), etc (Alajmi 2011; Ardali et al. 2012, Rubin and Izgec2015; Temized et al. 2016, CMG 2011). The other is in situ combustion which generates heat in reservoir by combustion (Hascakir and Kovscek 2014; Ismail et al. 2016). Among the many techniques, CSS and SF are the most widely used.

During the middle-late stages of steam injection processes, steam channeling and steam override occur and become more and more serious, resulting in poor development effect of CSS and SF. It mainly results in decreased daily oil production, increased water cut, and low cumulative oil-steam ratio (OSR). In general, the average oil recovery of CSS after eight cycles is about $20 \%$ and that of $\mathrm{SF}$ is $40-50 \%$. That suggests the heavy oil reservoirs have huge developing potential after steam injection. Hot-water flooding is considered as an effective EOR technique for heavy oil after steam injection (8, Diaz-Munoz and Farouq

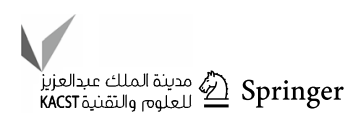


Ali 1975; Fournier 1965; Harmsen 1971; Tagavifar et al. 2016; Zhao and Gates2013; Luo and Torabi2013). It can not only continue to heat the reservoir, but also make use of the residual heat of steam. Compared with other thermal recovery methods, the sweep area in the hot-water flooding process mainly locates in the bottom of the reservoir, in spite of the permeability of the upper layer being higher than that of the bottom. The EOR mechanisms of hot-water flooding include (1) heating and viscosity reduction-heavy oil viscosity reduces dramatically with the increase of temperature, which decreases viscosity fingering and then improves areal sweep efficiency. (2) Pressure maintenance-similar to conventional water flooding, hot-water flooding can maintain reservoir pressure and supplement displacement energy. (3) Mobility ratio reduction-as oil viscosity is decreased, the mobility ratio between oil and water also decreases so much that oil-flow ability increases. (4) Sweep efficiency improvement - the injected steam usually flows to the upper layer of the reservoir preferentially due to its lower density, while the injected hot-water can carry the retained heat of steam to the bottom region under the action of gravity because of its higher density, thus improving the vertical sweep efficiency of the reservoir. (5) The thermal expansion of rock and fluid-the injection of hot-water causes thermal expansion of rock and fluid in the reservoir, which is beneficial for formation pressure recovery. But for reservoir that is flooded by hot-water after steam injection, this effect is not very obvious. As thermal expansion of rock and fluid is much stronger. (6) Relative permeability and wettability alteration-as water temperature rises, polar substances such as asphaltene and colloid are not absorbed on the rock. The rock surface tends to be hydrophilic and the residual oil saturation declines.

As an approved alternative technique after steam injection, many scholars have done laboratory study and field application of hot-water flooding and summarized the advantages of hot-water flooding over SF in a thin heavy oil reservoir. Diaz-Munoz and Farouq Ali pointed out that HWF could provide larger displacement drive than steam flooding because water had a much greater viscosity than steam (Diaz-Munoz and Farouq Ali 1975). The heat loss to the overburden and understrata during HWF process is much smaller than that in a SF process due to the lower injection temperature. Furthermore, HWF can make use of much higher injecting pressure than steam-flooding at a given temperature. The 10-pattern steamflood, Kern River field in California was converted to water injection in Sept. 1975 after 7 years of operation. The post-steam water injection process helped to distribute residual heat and to maintain reservoir pressure, and contributed $22 \%$ of the oil in place (OIP) (Oglesby et al. 1982). The E29 hot-water-injection pilot in the Pelican Lake field is another successful application of the HWF technique. After hot-water circulation process, oil production increases from approximately $6 \mathrm{~m}^{3 /}$ day to over $25 \mathrm{~m}^{3} /$ day, and has held relatively steady for more than 2 years (Duval et al. 2015). In China, Du66 block in Liaohe oilfield has conducted the flexibility study of enhancing heavy oil recovery by injecting hot water into the reservoir in 2001, and yield a good oil production increment (Zhao 2005). Also, Jin 45 block in Liaohe oilfield, Bi125 block in Henan oilfield and Jiul block in Karamay oilfield have carried out the investigation of development method transformation after steam injection by both physical simulation and field application (Wu 1997; Li et al. 2005; Lin et al. 2007; Ma and Wang 1994).

The clastic rocks in the oil-bearing section of Jinglou oilfield include conglomerate, gravel sandstone, coarse sandstone, medium sandstone, siltstone, argillaceous siltstone, grey mudstone, shale and sandy shale. The reservoir is shallow but has strong heterogeneity while it is mediumporosity and high-permeability. Cyclic steam stimulation (CSS) was applied in B125 block of Henan oilfield since June 1990. In recent years, however, the development effect of CSS becomes poor. Under the condition of steam channeling and immature plugging technology, hot-water flooding was selected as an alternative development method and is applied in September 1996. After that, oil production was increased $0.25 \times 10^{4} \mathrm{t}$ per year, accounting to $5 \%$-oil recovery. In this paper, aimed at Jinglou block which has the similar geological property with B125 block in Henan oilfield, the study of enhancing heavy oil recovery by hotwater flooding after steam injection is performed from both physical simulation and numerical simulation aspects. In the laboratory experiments, the influence factors such as water temperature and converting moment are studied in a series displacement experiments with a sandpack. Afterwards, on the basis of the geological properties, the corresponding numerical models are built to study the influences of several sensitive factors (e.g., reservoir thickness, reservoir rhythm and reservoir heterogeneity). Furthermore, the necessity of development method transformation in the late steam injection process is also presented intuitively with the numerical simulation method.

\section{Experiments}

\section{Experimental setup and materials}

\section{Apparatus}

The hot-water flooding experiment is conducted using a sand-pack that is $60 \mathrm{~cm}$ in length and $3.8 \mathrm{~cm}$ in inner diameter. The inner wall of the sand-pack is rough to prevent fluid bypassing and it is filled with glass beads of 80 mesh to form porous media. A precise pressure gauge is mounted 
on the sand-pack to record the inlet pressure during the displacement process. A back-pressure valve controlled by a hand-pump is installed at the outlet to simulate the formation pressure. The sand-pack is then put in a temperatureconstant oven at reservoir temperature. Steam (hot-water), crude oil and water are delivered into the sand-pack at a constant rate with the use of three ISCO pumps, respectively. The steam and hot-water are produced by a steam generator by adjusting its outlet temperature. To reduce the heat loss, the injection line is covered by an electric heater that is set at the steam generator temperature. The produced liquid is measured by a cylinder and the pressure and temperature are collected by a data acquisition unit which is connected to a computer.

\section{Materials}

The crude oil used for this study is from a heavy oil field of China. The properties of the oil sample are listed in Table 1.

\section{Experimental procedures}

After being filled with glass beads of 80 mesh, the sand-pack is examined for air tightness with nitrogen for $30 \mathrm{~min}$. To be better saturated with water, the sand-pack is first placed vertically and the water is injected into it from the bottom at an injection rate of $1 \mathrm{~mL} / \mathrm{min}$ until water occurs at the upper outlet. At this point, we consider most pores in the porous media are occupied by water because of relatively lower injection rate and gravity effect. Afterwards, the sandpack is put horizontally and another 5 PVs (pore volumes) water is injected when the pressure at the inlet is stable. The porosity and permeability of the sand-pack are calculated by substance conservation and Darcy's law, respectively. Then crude oil is injected into the sand-pack at the reservoir temperature until the oil cut at the outlet is $100 \%$. After that, the sand-pack is aged for $6 \mathrm{~h}$. Then, another three groups of displacement experiments are carried out with the sand-pack.

Two important factors, including water temperature and the moment that steam injection is converted into hot-water flooding are considered in the displacement experiments.

Table 1 Properties of heavy-oil sample

\begin{tabular}{ll}
\hline Property & Heavy oil \\
\hline Reservoir temperature $/{ }^{\circ} \mathrm{C}$ & 29.6 \\
API gravity ${ }^{\circ}$ & 22.3 \\
Oil viscosity at reservoir temperature/cp & 6,800 \\
Resins $/ \%$ & 33.47 \\
Asphaltenes $/ \%$ & 1.56 \\
\hline
\end{tabular}

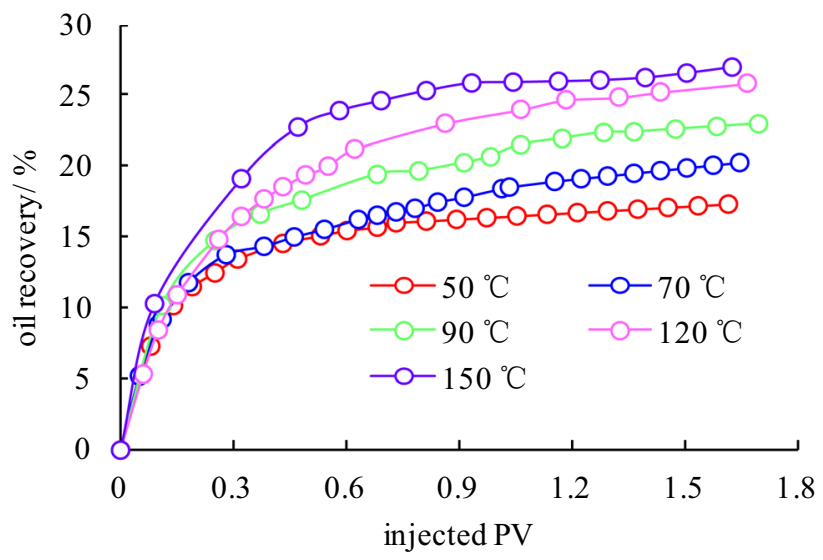

Fig. 1 Oil recovery varies with injected PVs at different temperatures

\section{Temperature}

Temperature is one of the key parameters that affect the development effect of viscous oil by HWF. Oil viscosity is sensitive to temperature and it decreases dramatically with the increase of temperature, which is beneficial for enhanced oil recovery. Experiments of different water temperatures are conducted to explore the effect of temperature on the HWF process. After the sand-pack is prepared, hot-water produced by a steam generator is injected into it at different temperatures, such as $50{ }^{\circ} \mathrm{C}, 70{ }^{\circ} \mathrm{C}, 90^{\circ} \mathrm{C}, 120^{\circ} \mathrm{C}$ and $150{ }^{\circ} \mathrm{C}$. The injection pipe is covered with an electric heater that can be set at the water temperature to keep the injected heat. During the displacement process, the sand-pack is put in a temperature-constant oven that is also at the experimental temperature.

\section{Converting moment}

On the basis of the first group of experiments, the appropriate moment that steam injection is converted into HWF is investigated. Converting into hot-water flooding at the right time can avoid the low efficient period of steam injection and maintain the stable yields of crude oil. The sand-pack is first refilled with glass beads and saturated with crude oil. The sand-pack is flooded by steam and then converted into HWF. In this part, four kinds of converting moments (namely oil recovery of steam flooding is $14.67 \%, 19.29 \%, 24.28 \%$ and $30.50 \%$, respectively) are designed to determine the reasonable converting moment.

\section{Experimental results and discussions}

Figure 1 presents the oil recovery variation at different temperatures. By the end (water cut $=98 \%$ ) of the displacement processes, the oil recovery of each temperature $(50,70,90$,

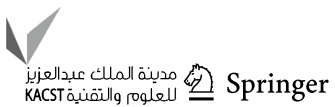


120 and $150{ }^{\circ} \mathrm{C}$ ) is $17.35 \%, 20.27 \%, 22.98 \%, 26.39 \%$ and $29.98 \%$, respectively. It shows that the oil production period increases first and then declines with the increase of temperature, and the temperature inflection point is $120^{\circ} \mathrm{C}$. This is because the viscosity ratio between oil and water is higher at lower temperatures, which results in water channeling in the tube, leading to poor development effect. As temperature rises, oil viscosity decreases dramatically and the mobility of crude oil increases. As a result, the production time is prolonged and the oil recovery is increased. But with the further increase in temperature, oil flowability is further strengthened. Therefore, the oil recovery is enhanced, and the production period is shortened as well. Figure 2 reflects that oil recovery increases as temperature increases, but amplification tends to be mild when the temperature reaches $120^{\circ} \mathrm{C}$. Consequently, the proper temperature of hot-water should be $120^{\circ} \mathrm{C}$.

From Figs. 3 and 4, it can be seen that the total oil recovery increases as the converting time is later, but it changes little when SF is converted to hot-water flooding at $24.28 \%$ oil recovery. Oil recovery during the hot-water flooding process varies a lot when converted at different moments. The stage oil recoveries are relatively lower when the oil recoveries in the SF process are $14.67 \%$ and $30.50 \%$. It is highest and reaches $24.56 \%$ when converted at $24.28 \%$-oil recovery. Therefore, the appropriate converting moment is when oil recovery during the steam flooding process reaches $24.28 \%$.

\section{Numerical simulation}

The study of numerical simulation is performed with the CMG STARS ${ }^{T M}$ thermal module (Computer Modelling Group (CMG) 2011). The viscosity-temperature relationships of the oil sample is shown in Fig. 5. The other basic

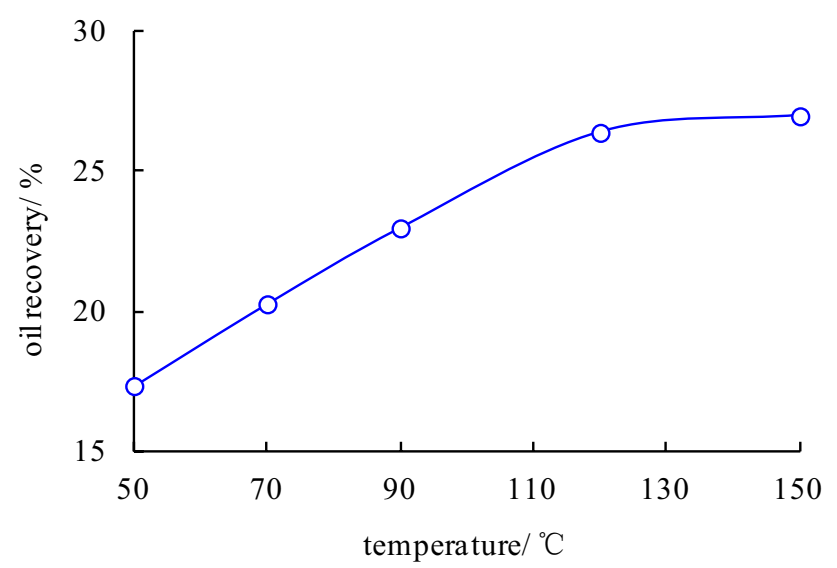

Fig. 2 Oil recovery at different temperatures

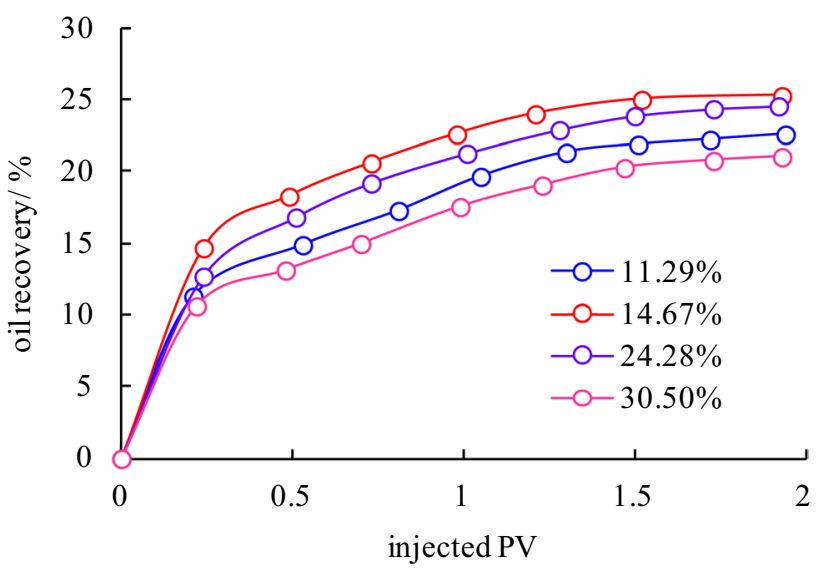

Fig. 3 Oil recovery varies with converting moment

data is shown in Table 2. The model is designed as $1 / 4$ ninepot pattern and the grid system is $21 \times 21 \times 3$.

The well group is conducted steam stimulation for eight cycles first. During this process, each well is injected steam for 10 days, soaked for 2 days and operates for 5 months. The steam temperature and steam quality is $300^{\circ} \mathrm{C}$ and 0.7 , respectively. Steam injection rate of the first cycle is $120 \mathrm{~m}^{3} /$ day and the growth rate is $10 \%$ from the first to the fourth cycle. The steam injection rate of each cycle is presented in.

Table 3. After that, the group is converted into hot-water flooding. Based on the numerical model, the effects of geological parameters including reservoir thickness, reservoir rhythm, and reservoir heterogeneity are studied for hot-water flooding.

\section{The effect of reservoir thickness}

Reservoir thickness is an important factor that affects the development effect of steam injection. The development

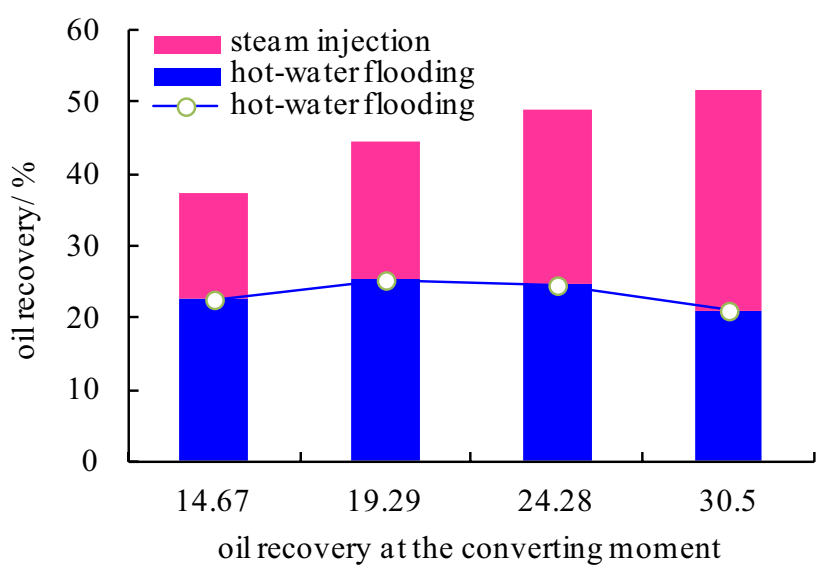

Fig. 4 Comparison of oil recovery at different converting moments 


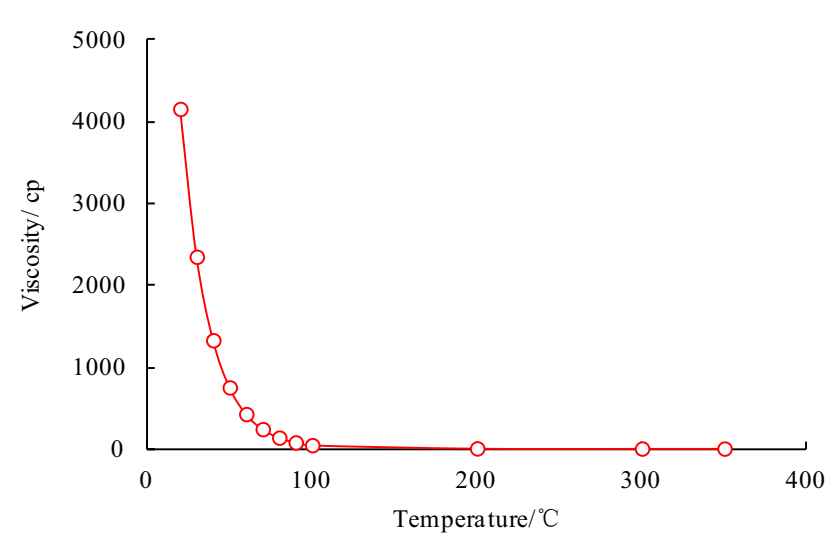

Fig. 5 Viscosity-temperature relationship of the oil sample

Table 2 Basic physical model parameters of the numerical

\begin{tabular}{ll}
\hline Parameter & Value \\
\hline Porosity/decimal & 0.3 \\
Permeability $/ \times 10^{-3} \mu \mathrm{m}^{2}$ & 2,000 \\
Initial oil saturation $/ \%$ & 65 \\
Net pay thickness $/ \mathrm{m}$ & 5 \\
Top depth/m & 500 \\
\hline
\end{tabular}

Table 3 Steam injection rate of each cycle

\begin{tabular}{llll}
\hline Cycle & $\begin{array}{l}\text { Steam injection rate/ } \\
\mathrm{m}^{3} \cdot \mathrm{d}^{-1}\end{array}$ & Cycle & $\begin{array}{l}\text { Steam injection } \\
\text { rate } / \mathrm{m}^{3} \mathrm{day}^{-1}\end{array}$ \\
\hline 1 & 120 & 5 & 160 \\
2 & 132 & 6 & 160 \\
3 & 145 & 7 & 160 \\
4 & 160 & 8 & 160 \\
\hline
\end{tabular}

methods used in a thick reservoir usually differ from that in a thin one. Thin reservoirs often cause serious heat loss. Thus, the heat efficiency of the injected hot medium is reduced. But in thick reservoirs, heat utilization may also be reduced because of steam override. In the simulation part, numerical models with thickness ranges from 3 to $6 \mathrm{~m}$ are built. The results are shown in Fig. 6. When the reservoir thickness is lower than $5 \mathrm{~m}$, oil recovery is enhanced remarkably as thickness increases. Oil recoveries for cases of $5 \mathrm{~m}$ and $6 \mathrm{~m}$ are $16.4 \%$ and $16.6 \%$, respectively, and it tends to be stable when the thickness is higher than $5 \mathrm{~m}$. As the thickness increases, the action of gravity becomes more and more serious, and the vertical sweep efficiency is limited. Therefore, the reservoir thickness limit that is suitable for hot-water flooding is $5 \mathrm{~m}$.

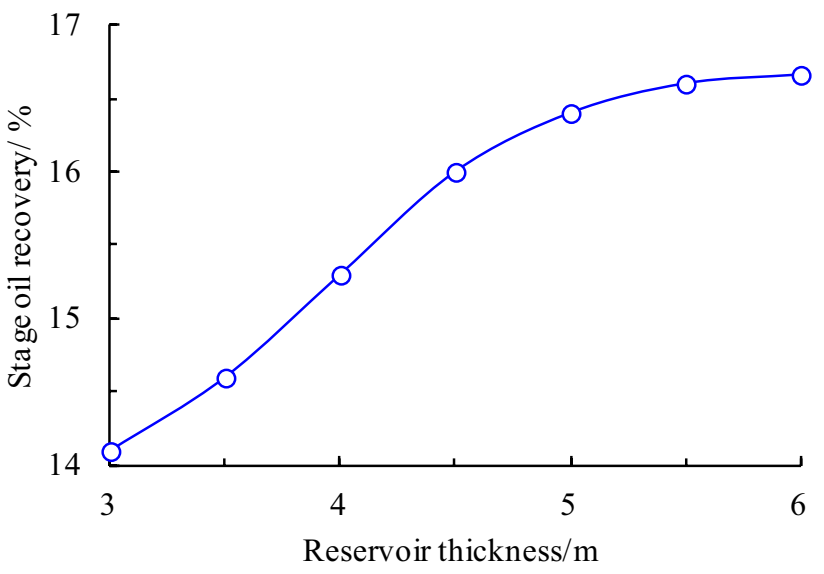

Fig. 6 Influence of reservoir thickness

\section{The effect of reservoir rhythm}

Considering the influence of reservoir rhythm on hot-water flooding, five kinds of rhythm-reservoirs are established, as shown in Fig. 7.

Permeability increases longitudinally from the top to the bottom in a positive-rhythm reservoir. Meanwhile, the injected hot-water migrates to the bottom under the action of gravity. Therefore, the water invasion at the bottom is serious, while the sweep efficiency at the upper is very limited. Low oil viscosity and high temperature are distributed in the near wellbore area of the injector. Gravity segregation, together with the high permeability at the bottom of positive-rhythm reservoir makes the hot-water mainly moves to the bottom of the reservoir, making a poor development effect of hot-water flooding after steam stimulation.

In reverse-rhythm reservoir, permeability decreases longitudinally from the top to the bottom. Large quantities of the injected hot-water migrate at the middle and top. The bottom of the reservoir is also well swept because of gravity segregation. As a result, the total sweep efficiency of the reservoir is relatively high. Therefore, hot-water flooding is beneficial for improved sweep efficiency in reverse-rhythm reservoir after steam stimulation.

As for compound-rhythm (I) reservoir, permeability increases first and then decreases vertically. The injected hot-water mainly migrates at the middle part and the bottom is also swept due to gravity effect. While in compoundrhythm (II) reservoir, permeability decreases first and then increases vertically. Hot-water mainly moves at the top and the bottom, hence the heat frontier is perpendicular to the top and bottom layers. But the hot-water can still flow to the middle and bottom because of gravity and higher permeability at the bottom. In general, the middle and the bottom of the compound-rhythm reservoir are well swept and the overall sweep efficiency of the reservoir is good. 
Fig. 7 Schematic diagram of reservoir rhythm

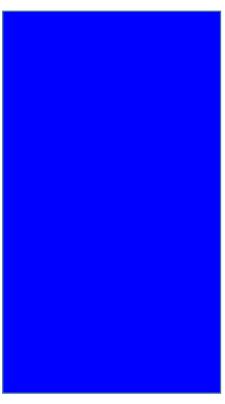

homogeneous

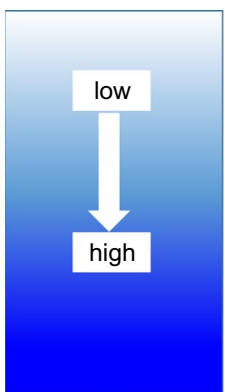

positive-

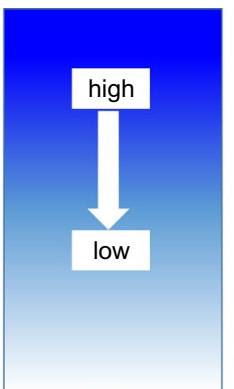

negativerhythm

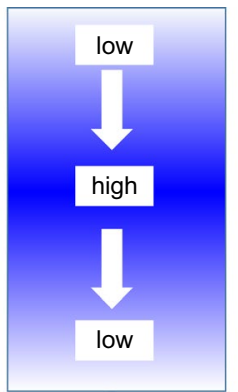

compoundrhythm (I)

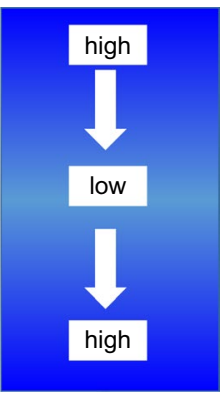

compoundrhythm (II)

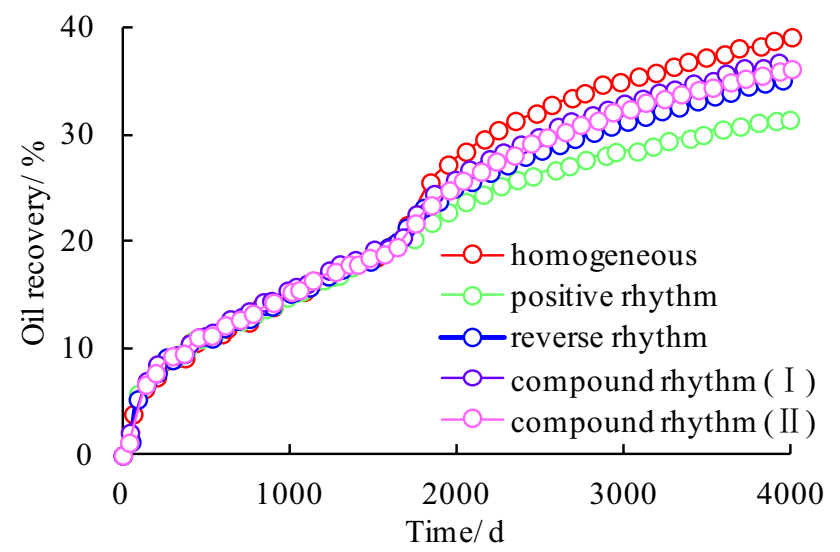

Fig. 8 Oil recovery variation in rhythm reservoirs

Figure 8 shows the oil recovery variation in reservoirs of different types. The oil recovery order is homogeneous reservoir $>$ compound-rhythm reservoir $>$ reverse-rhythm reservoir $>$ positive-rhythm reservoir. The oil recoveries in compound-rhythm and reverse-rhythm reservoirs are close, but higher than that in positive-rhythm reservoir. Oil recoveries at the end of steam stimulation processes in the five reservoirs are about $19 \%$, indicating that reservoir rhythm has little impact on steam stimulation. The ultimate oil recovery in homogeneous reservoir after hot-water flooding is about $38.19 \%$, however, those in the other reservoirs positive-rhythm, reverse-rhythm, compound-rhythm (I) and compound-rhythm (II) are $32.61 \%, 36.02 \%, 36.66 \%$ and $36.10 \%$, respectively. The results show that heavy oil recovery can be further improved by hot-water flooding after steam stimulation. The development effect in positiverhythm reservoir is relatively poor. But this technique is suitable for reverse-rhythm and compound-rhythm reservoirs.

\section{The effect of reservoir heterogeneity}

Reservoir heterogeneity which reflects the interlay contradiction is an important factor that limits the development effect of thermal recovery methods (Hascakir and Kovscek

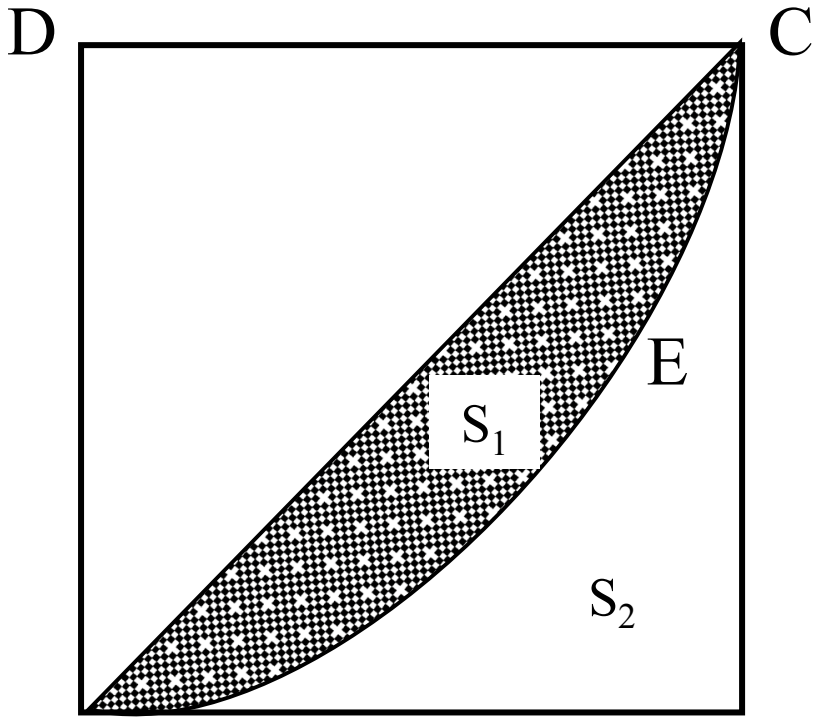

A

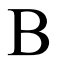

Fig. 9 Schematic diagram of Lorentz curve

2014; Al-Hadhrami et al. 2014; Yang and Butler 1992). On the basis of the analysis above, the influence of reservoir heterogeneity is studied. The interlayer heterogeneity in the reverse-rhythm reservoir is expressed by the use of Lorentz curve (Dong et al. 2011), as shown in Fig. 9. The Lorentz coefficient is the ration between $S 1$ and $S_{1}+S_{2}$. $S_{1}$ and $S_{2}$ is the area of the bow and triangle, respectively. When the reservoir is homogeneous, $S_{1}$ is zero. The permeability of each layer will be obtained if the Lorentz coefficient (Vk) is given. In the simulation models, the average permeability is given as $2000 \times 10^{-3} \mu^{2}$, and the Lorentz coefficients are 0 , $0.1,0.3,0.5,0.7,0.9$. The permeability distribution is shown in Table 4 and the simulation results are shown in Fig. 10.

When the $\mathrm{Vk}$ is less than 0.3 , namely the reservoir heterogeneity is low, the steam injection and hot-water flooding processes both can yield relatively high oil recovery. But when the Vk is higher than 0.3, reservoir heterogeneity becomes serious, and the oil recovery obtained by steam 
Table 4 Permeability distribution in different layers

\begin{tabular}{|c|c|c|c|c|c|c|c|}
\hline \multirow{2}{*}{\multicolumn{2}{|c|}{$\begin{array}{l}\text { Permeability } \\
\left(\times 10^{-3} \mu \mathrm{m}^{2}\right)\end{array}$}} & \multicolumn{6}{|l|}{$\mathrm{Vk}$} \\
\hline & & 0 & 0.1 & 0.3 & 0.5 & 0.7 & 0.9 \\
\hline \multirow[t]{3}{*}{ Layer } & 1 & 2000 & 2400 & 3464 & 4160 & 4996 & 5662 \\
\hline & 2 & 2000 & 1878 & 1434 & 1080 & 610 & 210 \\
\hline & 3 & 2000 & 1720 & 1100 & 758 & 392 & 126 \\
\hline
\end{tabular}

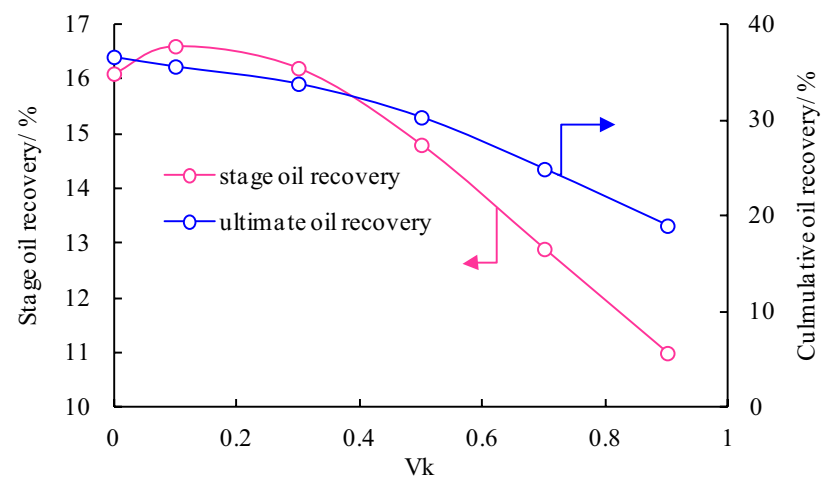

Fig. 10 Oil recovery variation with $\mathrm{Vk}$

and hot-water is decreased. With the further increase of Vk, the interlayer contradiction is strengthened. The displacement fluid mainly flows across the high-permeability area, and the low-permeability region cannot be fully mobilized. Consequently, the vertical sweep efficiency is poor, and no good development effect can be obtained.

\section{The discussion of the necessity of development method transformation}

Choosing the suitable moment converting steam stimulation into hot-water flooding is beneficial to get greater oil production at lower energy consumption. When steam stimulation is converted to hot-water flooding. The remaining oil assembles at the middle of the block which is the "dead oil" region that cannot be displaced by steam stimulation. To improve the reservoir producing degree, it is necessary to convert steam stimulation to other development methods, such as steam flooding, hot-water flooding, etc. However, heat loss is usually serious during steam flooding process due to the thin oil layer in Henan Oilfield of China. Therefore, hot-water flooding is proposed as an alternative of steam stimulation. The inter-well thermal communication is not generated completely, and the injected hot-water can flow to the corner well instead of moving directly to the edge wells that are closer to the injection well, thus improving the hot-water sweep efficiency. Additives such as foam and gel are usually used in hot-water flooding process for profile control and makes hot-water migrate to regions that remaining oil assembles. In addition, the water-alternating-gas method also does good to increase injected heat to the reservoir, thus decreasing oil viscosity and increasing crude oil mobility.

\section{Conclusions}

In this paper, the performance of hot water to displace the conventional heavy oil after steam injection is investigated. On the basis of the experimental and numerical simulation results, several conclusions are obtained as follows:

1. The optimized water temperature is $120^{\circ} \mathrm{C}$. When the hot-water temperature is kept at $120^{\circ} \mathrm{C}$, hot-water flooding can obtain the best oil recovery and the lowest residual oil saturation.

2. Numerical simulation results show that large quantities of remaining oil assemble at the inter-well region of a five-spot well pattern during the late stage of the steam injection process, and cannot be swept by steam. The best converting moment is when the oil recovery of steam injection reaches $24 \%$. Hot-water flooding can extend oil production period, thus increasing oil recovery.

3. The hot-water flooding process is suitable to the thin heavy oil reservoirs in Henan oilfield with thickness lower than $5 \mathrm{~m}$ and permeability variation coefficient less than 0.3 . The effect of hot-water flooding in reverserhythm reservoir and compound-rhythm reservoir is relatively satisfactory, but that is bad in positive-rhythm reservoir due to the action of gravity.

Acknowledgements The authors acknowledge the experimental support from China University of Petroleum-Beijing.

\section{Compliance with ethical standards}

Conflict of interest The authors declare no competing financial interest.

Open Access This article is distributed under the terms of the Creative Commons Attribution 4.0 International License (http://creativeco mmons.org/licenses/by/4.0/), which permits unrestricted use, distribution, and reproduction in any medium, provided you give appropriate credit to the original author(s) and the source, provide a link to the Creative Commons license, and indicate if changes were made. 


\section{References}

Alajmi H, King PP (2011) Assessment of thermal EOR methods for a heavy-oil sandstone reservoir in Middle East. In: Proceedings of the SPE enhanced oil recovery conference, Kuala Lumpur, Malaysia, July 19-21, 2011; SPE: Richardson, TX

Al-Hadhrami MM, Alkindi AS, Muggeridge AH (2014) Experimental and numerical investigations into the effect of heterogeneities on the recovery of heavy oil by VAPour EXtraction (VAPEX). Fuel 135:413-426

Ardali M, Barrufet M, Mamora DD, Qiu F (2012) A critical review of hybrid steam/solvent processes for the recovery of heavy oil and bitumen. In: Proceedings of the SPE annual technical conference and exhibition, San Antonio, Texas, October 8-10; SPE: Richardson, TX, 2012

Bogdanov I, Torres J, El Ganaoui K, Kamp AM (2010) The influence of salt concentration in injected water on low frequency electricalheating assisted bitumen recovery. In: Proceedings of the SPE improved oil recovery symposium, Tulsa, Oklahoma, April 24-28; SPE: Richardson, TX, 2010

Computer Modelling Group (CMG) (2011) CMG Ltd. STARS user's manual, version 2011.10. Calgary. Computer Modelling Group, Alberta

Diaz-Munoz J, Farouq Ali SM (1975) Effectiveness of hot-water stimulation of heavy-oil formations. J Can Petr Techn 14(03):65-76

Dong X, Liu H, Zhang H, Pang Z (2011) Flexibility research of hotwater flooding followed steam injection in heavy oil reservoirs. In: Proceedings of the SPE enhanced oil recovery conference. 19-21 July, Kuala Lumpur, Malaysia

Duval K, Gutiérrez D, Petrakos D, Ollier PM, Johannson DM (2015) Successful application of hot water circulation in the Pelican Lake Field-results and analyses of the E29 hot water injection pilot. J Can Petr Techn 54(6):361-371

Fournier KP (1965) A numerical method for computing recovery of oil by hot water injection in a radial system. SPE J 5(02):131-140

Harmsen GJ (1971) Oil recovery by hot-water and steam injection. In: Proceedings of the 8th world petroleum congress, Moscow, USSR, June 13-18

Hascakir B, Kovscek AR (2014) Analysis of in-situ combustion performance in heterogeneous media. In: Proceedings of the SPE heavy oil conference-Canada, Calgary, Alberta, Canada, June 10-12, 2014; SPE: Richardson, TX

Ismail NB, Klock KA, Hascakir B (2016) In-situ combustion experience in heavy oil carbonate. In: Proceedings of the SPE Canada heavy oil technical conference, calgary, Alberta, Canada, June 7-9, 2016; SPE: Richardson, TX

Li J, Kang Y, Gao X (2005) The possibility study of the hot-water drive techniques in Bi125 area of Henan Oil Field. West-China Expl Eng 17(6):73-74
Lin Y, Yang C, Zhao H (2007) Optimization study on development scheme conversion after cyclic steam stimulation for conventional heavy oil reservoir. Sino-Global Energy 12(3):46-50

Luo W, Torabi F (2013) Coupling of solvent and hot water to improve heavy oil recovery: experimental and simulation studies. In: Proceedings of the SPE Heavy oil conference-Canada, Calgary, Alberta, Canada, June 11-13, 2013; SPE: Richardson, TX

Ma X, Wang L (1994) The influence of water injection method on the development effect of hot-water flooding after steam flooding in Jiu1 Block. Xinjiang Pet Technol 4(4):50-55

Oglesby KD, Blevins TR, Rogers EE, Johnson WM (1982) Status of the 10-Pattern steamflood, Kern River Field, California. J Pet Technol 34(10):2251-2257

Rubin E, Izgec O (2015) Forecasting of steamflood performance in a heavy oil field. In: Proceedings of the SPE annual technical conference and exhibition, Houston, Texas, USA, September 28-30, 2015; SPE: Richardson, TX

Tagavifar M, Fortenberry R, de Rouffignac E, Sepehrnoori K, Pope GA (2016) Heavy-oil recovery by combined hot water and alkali/ cosolvent/polymer flooding. SPE J 21(01):74-86

Temized C, Balaji K, Coman C (2016) Optimization of steamflooding heavy oil reservoirs under uncertainty. In: Proceedings of the SPE Asia Pacific Oil and gas conference and exhibition, Perth, Australia, October 25-27, 2016; SPE: Richardson, TX

Trigos EM, Avila RD, Lozano ME, Jimenez AM, Osorio CA (2016) Strategies to increase production in a colombian heavy oil field with cyclic steam stimulation. In: Proceedings of the SPE Latin America and Caribbean heavy and extra heavy oil conference, Lima, Peru, October 19-20, 2016; SPE: Richardson, TX

Wu J (1997) Physical simulation on hot-water injection and intermittent steam injection at the late stage of steam flooding for heavy oil. Xinjiang Pet Technol 3(7):12-21

Yang G, Butler RM (1992) Effects of reservoir heterogeneities on heavy oil recovery by steam-assisted gravity drainage. J Can Pet Technol 31(8):37-43

Zhao Q (2005) A feasibility study of hot-water injection development for thin-interbedded reservoir with heavy oil: a case of lower interval of Du66 block in Shuguang oilfield, Liaohe Area. China Offshore Oil Gas 17(4):251-255

Zhao D, Gates I (2013) Stochastic optimization of hot water flooding strategy in thin heavy oil reservoirs. In: Proceedings of the SPE Heavy Oil Conference Canada, Calgary, Alberta, Canada, June 11-13, 2013; SPE: Richardson, TX

Publisher's Note Springer Nature remains neutral with regard to jurisdictional claims in published maps and institutional affiliations. 